\title{
Effect of moisture stress on physiological mechanisms in drought tolerance in selected genotypes of groundnut (Arachis hypogaea L.)
}

\author{
H. Y. Patil*, Pooja and V. P. Chimmad \\ Department of Crop Physiology, College of Agriculture, University of Agricultural Sciences, Dharwad \\ (Karnataka) India \\ (Email: patil_hy@rediffmail.com;patilhy@uasd.in)
}

\begin{abstract}
Eight groundnut genotypes of including four released and pre-released genotypes were evaluated for moisture stress at pegging $\left(\mathrm{M}_{2}\right)$ and pod development $\left(\mathrm{M}_{3}\right)$ stage stress situations with control $\left(\mathrm{M}_{1}\right)$ during post-rainy season (Nov-April), 201819 at University of Agricultural Sciences, Dharwad and Karnataka, India. The drought stress was imposed by with holding irrigation at 40-80 DAS $\left(\mathrm{M}_{2}\right)$ and 80 DAS-harvest $\left(\mathrm{M}_{3}\right)$. Observations were recorded for physiological parameters like leaf area, SPAD readings, chlorophyll content, stomatal frequency, photosynthetic rate and pod yield per plant. Among the selected genotypes, GPBD-4, Dh-257 and Dh-256 are considered as drought tolerant genotypes at both the stress levels based on lesser reduction in leaf area, optimum chlorophyll content and photosynthetic rate, less leaf folding and by these adaptations recorded reduced reduction in pod yield over control. Genotypes, Dh-86 and TMV-2 affected severely by drought at both the stages. But higher effect was observed under pod developmental stage stress.
\end{abstract}

Key Words : Drought stress, Physiological parameters, Soil moisture stress, SPAD, Relative leaf chlorophyll content

View Point Article : Patil, H.Y., Pooja and Chimmad, V.P. (2020). Effect of moisture stress on physiological mechanisms in drought tolerance in selected genotypes of groundnut (Arachis hypogaea L.). Internat. J. agric. Sci., 16 (2) : 277-283, DOI:10.15740/HAS/IJAS/ 16.2/277-283. Copyright@2020: Hind Agri-Horticultural Society.

Article History : Received : 10.04.2020; Revised : 23.05.2020; Accepted : 28.05.2020

\footnotetext{
* Author for correspondence:
} 